\title{
Premorbid prevalence of poor academic performance in severe head injury
}

\author{
JANET F HAAS, ${ }^{*}$ D NATHAN COPE, $\dagger$ KARYL HALL $\ddagger$ \\ From Temple University, Philadelphia, Pennsylvania, ${ }^{*}$ Division of Rehabilitation Medicine, Stanford \\ University School of Medicine, Stanford, California, $\uparrow$ Northern California Regional Spinal Injury System, \\ Institute for Medical Research, $\ddagger$ San Jose, California, USA
}

SUMMARY A study of 80 head injured patients revealed poor premorbid academic performance in up to $50 \%$ of the sample. Poor academic performance, as defined by diagnosis of learning disability, multiple failed academic subjects, or school dropout during secondary education, is not a previously cited risk factor for head injury. These findings have important implications in the identification of a high risk population and in the subsequent ability to reduce the incidence of head injury.

Head injury is the major cause of disability in the young adult. In 1974, 50 million Americans suffered accidental injury; head injury, sustained in 3 million, led to $70 \%$ of the subsequent deaths. ${ }^{1}$ Traumatic head injury presents a major health problem; in the United States in 1974, 422,000 new cases occurred, a rate of 200 head injuries $/ 100,000$ population per year. ${ }^{2}$

The costs relative to head injury are staggering. American figures published in 1980 estimate 3.9 billion dollars per year. ${ }^{2}$ Medical expenses account for one-third; social costs, such as disability payments and lost income, comprise two-thirds. It is likely that these costs are underestimated. Dollar figures do not encompass the cost of suffering in human terms.

To date, no treatment after severe head injury is totally restorative; in this context, avoidance of such injury becomes critical. Efficient preventive efforts require knowledge of risk factors. It is known that $63 \%$ of victims are younger than 25 years of age and males outnumber females by more than two to one. Over half of the injuries result from motor vehicle accidents and more than $60 \%$ of the drivers have elevated blood alcohol levels. Thus, persons most at risk for head injury are adolescent and young adult males operating a motor vehicle while intoxicated. ${ }^{3}$

Several authors imply that head injury occurs primarily in persons who functioned suboptimally premorbidly. Fahy et $\mathrm{al}^{4}$ found that $46 \%$ of their patients had been "maladjusted in some way". Fuld and

Address for reprint requests: Dr Nathan Cope, M.D., HRP Building, Room 106 A., Stanford University Medical Center, Stanford, CA 94305, USA.

Received 8 December 1983 and in final revised form 16 July 1985. Accepted 28 September 1985.
Fisher ${ }^{5}$ noted that only three of 18 head injured children had been normal academically and socially before the accident. Fell, ${ }^{6}$ investigating fatal motor vehicle accidents in four US cities, reported elevated blood alcohol levels in offenders. The typical offender was a 20-35 year old single or divorced male, with a 12 th grade education at best, and often with a history of driving violations, including a suspended licence.

\section{Minimal brain dysfunction and hyperactivity}

There are several studies, such as that of Laufer and Denhoff ${ }^{7}$ in 1957, which have concluded that hyperactivity disappears by early adulthood. However, it is more recently generally acknowledged that persons with one of a number of diagnoses in childhood, including minimal brain dysfunction and hyperactivity, may continue to encounter problems as adults. Other studies demonstrate that children with minimal brain dysfunction and hyperactivity may continue to be impulsive and distractible as adults, and may develop psychosis, alcoholism, addiction, sociopathy and personality deficits. ${ }^{8-12}$

\section{Learning disability}

There are fewer studies concerning the developmental outcome of children with learning disability. Ackerman et al $^{13}$ and Wender ${ }^{14}$ reported that some authors believe that difficulties are outgrown during the maturational process. Conversely, $\operatorname{Cox}^{15}$ stated that lack of self-confidence and below average career success are common, and Culbertson and Ferry ${ }^{16}$ described persistence of learning problems into adult life. Weiner ${ }^{17}$ postulated that poor peer relationships result from deficiencies in interpersonal cognitive problem-solving skills. Kronick, ${ }^{18}$ too, cited that 
interactional inadequacies of learning disability children become paramount after they leave school. Deficits are noted in social perceptiveness, judgement, concentration, capacity for intimacy, and strength of self-concept. Such persons profit poorly from previous experiences, and may be unsuccessful in vocational, marital, and parenting roles.

Other authors, discussing problems encountered in adolescence, make particular reference to the high percentage of juvenile delinquents who, upon investigation, have learning disability. ${ }^{19-21}$ Mauser $^{22}$ described eight similarities between learning disability and juvenile delinquency, although Spreen ${ }^{23}$ disputed this connection in a 4-12 year follow-up of 203 learning disability children.

The prevalence of learning disability is quoted as anywhere from $1 \%$ to $20 \%$ of school-aged children. ${ }^{24}$ Most estimates are between $2 \%$ and $4 \%$ in the United States. ${ }^{16}$

\section{Academic failure}

Information concerning the outcome of the majority of students with academic failure, who have not been specifically diagnosed as having attention deficit disorder, minimal brain dysfunction, hyperactivity, or learning disability, is elusive. ${ }^{25}$ Most articles about underachievers and dropouts discuss aetiology, treatment, and prevention, rather than longterm outcome. $^{26}$ Beck and $\mathrm{Muia}^{27}$ do, however, allude to interpersonal alienation and inability to hold a job as part of the dropout syndrome.

The national dropout rate from high school is estimated at anywhere between $11 \%$ and $28 \%$, with an overall figure of $23 \%{ }^{28}$ The dropout rate for California is estimated at between $16.8 \%$ and $30 \% .{ }^{2829}$ The higher rates apply, in general, for inner city, ghetto, or minority student populations.

During the course of a formal, prospective study of 80 traumatically head injured patients, ${ }^{30}$ a surprising number were noted to have been poor students premorbidly. This observation suggested the hypothesis that poor academic performance is an additional, previously unreported indicator of an increased risk of head injury.

\section{Methods}

The subjects of this investigation were 80 patients sequentially admitted to the Santa Clara Valley Medical Center (SCVMC) in San Jose, California. All had suffered severe blunt traumatic head injury from one to 18 months prior to admission. They met the following criteria: (1) admission as inpatient to the SCVMC acute head injury rehabilitation unit; (2) comatose for longer than 6 hours; and (3) between 15 and 60 years of age. Demographic characteristics of the 80 patients were similar to those reported in other head injury studies. Sixty-one per cent of the patients were 25 years of age or younger, the male to female ratio was $2 \cdot 5: 1$, and motor vehicle accident was the aetiology of injury in $69 \%$ of the cases. Ethnic minorities comprised $20 \%$ of the 80 patients.

Parameters selected to indicate poor scholastic achievement were: (1) multiple (two or more) failed academic subjects in one semester; (2) school dropout; or (3) premorbid diagnosis of learning disability. Information was obtained from school records, reports of premorbid examinations by paediatricians and school psychologists, and interviews with the patients' parents during and after hospitalisation.

The medical records of all 80 patients were reviewed. Subsequently patients were divided into two groups: those born prior to 1952 , educated before learning disability was widely recognised within the educational system, and those born during or after 1952, educated after public laws mandating identification of learning disability had generally been enacted.

\section{Results}

Of the 80 patients, $27(33.7 \%)$ were reported as having demonstrated poor academic achievement or had been designated learning disabled. Exclusion of the 16 patients for whom information about school performance was not available reduced the number to 64 patients. The 27 underachievers represent $42 \cdot 2 \%$ of this group (tables 1 and 2).

Twenty-eight of the total group of 80 patients were born prior to 1952 . Of this group, four, or $14.3 \%$ failed in school. Exclusion of 10 patients of the 28, those for whom records are incomplete, reduces the total to 18 , of whom the four underachievers comprise $22 \cdot 2 \%$.

Fifty-two patients were born during or after 1952 . Of this group, 23 or $\mathbf{4 4 . 2 \%}$ had poor premorbid academic histories. Exclusion of the six patients with incomplete records reduces the total to 46 ; of this group, the 23 poor achievers represent $50 \%$. (The higher prevalence of poor achievers born after 1951 may reflect the impact of public legislation which promoted identification of those with learning disability or a reduction in relative risk with age.)

In the group of 23 poor achievers born during or after 1952, the male:female ratio was 3:1. Aetiology of head injury was motor vehicle accident in $61 \%$, pedestrian versus motor vehicle in $22 \%$, and altercation in $\mathbf{9 \%}$.

\section{Discussion}

Our results indicate that $50 \%$ of severely head-injured patients who were educated after learning disability was well known, demonstrated poor premorbid academic performance. This association suggests that persons who have done poorly in school have a definite increased risk of sustaining head injury. We 
Table 1 Prevalence of premorbid academic failure in severely head injured patients

\begin{tabular}{|c|c|c|c|c|c|c|}
\hline \multirow[b]{2}{*}{ Category } & \multicolumn{4}{|l|}{ Date of birth } & \multirow[b]{2}{*}{$\begin{array}{l}\text { Total } \\
N\end{array}$} & \multirow[b]{2}{*}{ Per cent } \\
\hline & $\underset{N}{\text { Prior to } 1952}$ & Per cent & $\begin{array}{l}1952 \text { and later } \\
N\end{array}$ & Per cent & & \\
\hline \multicolumn{7}{|l|}{ Academic failure } \\
\hline Learing disability & 0 & 0 & 8 & $15 \cdot 4$ & & \\
\hline $\begin{array}{l}\text { Dropout } \\
\text { Multiple F's }\end{array}$ & $\begin{array}{l}2 \\
2\end{array}$ & $\begin{array}{l}7 \cdot 2 \\
7 \cdot 2\end{array}$ & $\begin{array}{r}10 \\
5\end{array}$ & $\begin{array}{r}19 \cdot 2 \\
9.6\end{array}$ & 27 & $33 \cdot 8$ \\
\hline No academic failure & 14 & $50 \cdot 0$ & 23 & $44 \cdot 2$ & 37 & $46 \cdot 2$ \\
\hline Inadequate information & 10 & $35 \cdot 7$ & 6 & $11 \cdot 5$ & 16 & $20 \cdot 0$ \\
\hline Total & 28 & $100 \cdot 0$ & 52 & $100 \cdot 0$ & 80 & $100 \cdot 0$ \\
\hline
\end{tabular}

do not define impaired scholastic performance as a specific syndrome; rather, it is a constellation of symptoms which includes multiple failing grades, school dropout, or learning disability.

Multiple failing grades are readily documented. Dropouts are students who leave school and do not return within that educational year. Such failure may reflect a student's difficulties with language or academic skills, lack of guidance, a poor social environment, behavioural difficulties, boredom, or limited flexibility of educational programs.

The concept of learning disability developed in the US in the 1950s and $1960 \mathrm{~s},{ }^{31}$ with passage of legislation ${ }^{32}$ assuring its widespread recognition by 1970. It usually describes children of at least average intelligence who demonstrate impaired perception, cognition, gross or fine motor skill, or language development, and who function from one to several years behind grade level in at least one academic subject. ${ }^{33} 34$ With time, the boundaries of this syndrome have blurred into those of minimal brain dysfunction, hyperactivity, and attention deficit disorder. ${ }^{3536}$ In other countries there is less tendency to categorise behavioural and educational dysfunction. In fact, a British paediatric neurologist has written that minimal brain damage is not a diagnosis; it is an escape from making one. ${ }^{37}$

Although the systems and language of evaluation vary between countries, a universal fact is that some students suffer academic failure. While congruence of terms between educational systems would be ideal, this is not essential to recognise students who are at risk.

Our results reveal that a higher percentage of headinjured patients had a history of poor academic per- formance than would be expected based upon even the most generous estimates of dropout prevalence (50\% in the study after 1951 , as contrasted to a dropout rate of between 17 and $30 \%$ state-wide). The statewide rate cannot be compared directly to the prevalence of poor academic history in our sample because the state maximum figure of $30 \%$ includes only dropouts, rather than those with learning disability or failed classes. Nevertheless, it appears that the sample does have a significantly higher prevalence of premorbid problems than the general public.

Several explanations may account for this high prevalence. Perhaps the apparent increased risk of head injury results from continued expression of the primary symptomatology of these children. Distractibility, poor attention span, or inability to focus upon relevant factors may predispose to accidents. Limited frustration tolerance, impulsivity, or poor judgement may do likewise. Deficiency in ability to anticipate situations accurately and to plan appropriately may render persons vulnerable to accident. Perceptual-motor deficits, figure-ground confusion, difficulty with spatial relationships, and cognitive impairment persisting into adulthood may compromise one's ability to process incoming information correctly, or to respond in a precise, calculated manner.

Alternatively, head injury may result from developments which occur as secondary processes. Children who fail in school may grow up socially stigmatised, with feelings of rejection, inferiority and isolation. They may become rebellious, egocentric, and sociopathic, and less able to cope well with the increasing responsibilities of adolescence and adulthood. Substance abuse may occur and predispose to accidental

Table 2 Prevalence of premorbid academic failure excluding patients with inadequate information on academic performance

\begin{tabular}{|c|c|c|c|c|c|c|}
\hline \multirow[b]{2}{*}{ Category } & \multicolumn{4}{|l|}{ Date of birth } & \multirow[b]{2}{*}{$\begin{array}{l}\text { Total } \\
N\end{array}$} & \multirow[b]{2}{*}{ Per cent } \\
\hline & $\begin{array}{l}\text { Prior to } 1952 \\
N\end{array}$ & Per cent & $\begin{array}{l}1952 \text { and later } \\
N\end{array}$ & Per cent & & \\
\hline $\begin{array}{l}\text { Academic failure } \\
\text { No academic failure } \\
\text { Total }\end{array}$ & $\begin{array}{r}4 \\
14 \\
18\end{array}$ & $\begin{array}{r}22 \cdot 2 \\
77 \cdot 8 \\
100 \cdot 0\end{array}$ & $\begin{array}{l}23 \\
23 \\
46\end{array}$ & $\begin{array}{r}50.0 \\
50.0 \\
100.0\end{array}$ & $\begin{array}{l}27 \\
37 \\
64\end{array}$ & $\begin{array}{r}42.2 \\
57 \cdot 8 \\
100 \cdot 0\end{array}$ \\
\hline
\end{tabular}


injury. Even the experience of previous single or multiple head injury may not provide protection against re-injury.

The findings of this study may have significant implications for formulation of rehabilitation goals and treatment plan. Both the rate and degree of the recovery process may be affected by premorbid limitations in academic performance.

These findings may also have significant implications for public health policy. Prevention of head injury is far more efficacious than any treatment currently available; therefore, the additional risk factor we have described should be addressed by preventive programmes. It is known that children who demonstrate poor academic achievement should be screened medically, provided special education classes for academic remediation, and taught basic socialisation skills. Counselling about alcohol, drugs, and vocational options is important. Our results indicate that safety awareness and intensive driver education with refresher courses may also be warranted. Drivers' licences could be granted later than the customary age of 16 to 18 years. In this identified population, driving violations, which indicate potential for future catastrophe, require serious attention. We believe that the findings of this study identify a previously unrecognised subpopulation at increased risk for significant head injury and for whom specific, preventive interventions may be indicated.

This research was supported in part by Grant No. G008202589, Project No. 128EH20015, from the National Institute of Handicapped Research, US Department of Education, Washington, DC 20202. Special thanks are due to Ms Sheilah Sanders for her assistance in data analysis.

\section{References}

1 Cartlidge NE, Shaw DA. Head Injury. London: WB Saunders, 1981:213.

2 Anderson DW, McLaurin RL, eds. The National head and spinal cord injury survey. J Neurosurg (Supplement) 1980;S21.

3 Jennett B, Teasdale G. Management of Head Injuries. Philadelphia: FA Davis Co, 1981:10-11.

4 Fahy TJ, Irving MH, Millac P. Severe head injuries. Lancet 1967;i:475-9.

5 Fuld PA, Fisher P. Recovery of intellectual ability after closed head-injury. Dev Med Child Neurol 1977;19: 495-502.

6 Fell JC. A profile of fatal accidents involving alcohol. In: Proceedings of the 21 st conference of the American Association for Automotive Medicine. Chicago: American Association for Automotive Medicine 1977; 197-218.

7 Laufer MW, Denhoff E. The hyperkinetic behavior syndrome in children. $J$ Pediatr 1957;50:463-74.
8 Eyre SL, Rounsaville BJ, Kleber HD. History of childhood hyperactivity in a clinic population of opiate addicts. J Nerv Ment Dis 1982;170:522-9.

9 Mendelson W, Johnson N, Stewart M. Hyperactive children as teenagers: a follow-up study. $J$ Nerv Ment Dis 1971;153:273-9.

10 Morrison JR. Diagnosis of adult psychiatric patients with childhood hyperactivity. Am J Psychiatry 1979; 136:955-8.

11 Weiss G, Minde K, Werry JS, Douglas V, Nemeth E. Studies on the hyperactive child. Arch Gen Psychiatry 1971;24:409-14.

12 Wood DR, Reimherr FW, Wender PH, Johson GE. Diagnosis and treatment of minimal brain dysfunction in adults. Arch Gen Psychiatry 1976;33:1453-60.

13 Ackerman PT, Dykman RA, Peters FJE. Teenage status of hyperactive and nonhyperactive learning disabled boys. Am J Orthopsychiatry 1970;47:577-96.

14 Wender P. The Hyperactive Child. New York: Crown Publishers, 1973:48.

15 Cox S. The learning-disabled adult. Acad Therapy 1977;13:79-86.

16 Culbertson J, Ferry P. Learning disabilities. Pediatr Clin N Am 1982;29:121-36.

17 Weiner J. A theoretical model of the acquisition of peer relationships of learning disabled children. $J$ Learning Disabil 1980;13:42-7.

18 Kronick D. An overview of research relating to the etiology of interactional deficits in the learning disabled. In: Knights RM, Bakker DJ, eds. Treatment of Hyperactive and Learning Disordered Children. Baltimore: University Park Press, 1980;395-401.

19 Bachara G, Zaba J. Learning disabilities and juvenile delinquency. J Learning Disabil 1978;11:242-5.

20 Berman A. Siegal A. A neurophysiological approach to etiology, prevention, and treatment of juvenile delinquency. In: Davis A, ed. Child Personality and Psychopathology, Current Topics. New York: John Wiley and Sons, 1976; vol 3.

21 Duling F, Eddy S, Risko V. Learning Disabilities of Juvenile Delinquents. Morgantown, West Virginia: Department of Educational Services, R.F. Kennedy Youth Center, 1970.

22 Mauser A. Learning disabilities and delinquent youth. Acad Therapy 1974;9:389-402.

23 Spreen $O$. The relationship between learning disability, neurological impairment, and delinquency. $J$ Nerv Ment Dis 1981;169:791-9.

24 Lambert NM, Sandoval J, Sassone D. Prevalence of hyperactivity in elementary school children as a function of social system definers. Am J Orthopsychiatry 1978;48:446.

25 Cannon IP, Compton CL. School dysfunction in the adolescent. Pediatr Clin N Am 1980;27:79-96.

26 Covington $\mathbf{M}$, Omelich $\mathrm{C}$. As failures mount: affective and cognitive consequences of ability demotion in the classroom. J Educ Psychol 1981;73:796-808.

27 Beck L, Muia J. A portrait of a tragedy: research findings on the dropout. High School Journal 1980;64:65-72.

28 Push out, step out: a report on California's public school drop-outs. Oakland CA: Open Road Research Project, Citizens Policy Center, 1982.

29 Guthrie JW, Kirst MW. Conditions of Education in Cali- 
fornia 1984. Policy Analysis for California Education. U.C. Berkeley, Stanford University 1984.

30 Collaborative. Severe head trauma: a comprehensive medical approach. San Jose, California: The Institute For Medical Research at Santa Clara Valley Medical Center, 1977-1981; Final Report of the Head Injury Rehabilitation Project. NIHR Grant \#13: 59156-9.

31 Kirk S, Kirk W. On defining learning disabilities. $J$ Learning Disabil 1983;16:20-21.

32 Lerner J. Children with Learning Disabilities: Theories, Diagnosis, and Teaching Strategies. Boston: Houghton Mifflin Co, 1971:13-22.
33 Gaddes WH. Learning Disabilities and Brain Function: $a$ Neuropsychological Approach. New York: SpringerVerlag, 1980:2212.

34 Millichap JG. Learning Disabilities and Related Disorders: Facts and Current Issues. Chicago: Yearbook Medical Publishers, Inc, 1977.

35 Gonzalez ER. Learning disabilities: lagging field in medicine. JAMA 1980;243:1883-92.

36 Komm R. He's "LD"-I mean he's "ADD". Acad Therapy 1982;17:431-5.

37 Ingram TTS. Soft signs. Dev Med Child Neurol 1973; 15:527-30. 